\title{
Experimental Analysis of Process Parameter Effects on Vibrations in the High-Speed Grinding of a Camshaft
}

\author{
Tao Liu1,2 - Zhaohui Deng1,2,* - Lishu Lv ${ }^{1,2}$ - Shuailong She1,2 - Wei Liu ${ }^{1,2}$ - Chengyao Luo ${ }^{1,2}$ \\ ${ }^{1}$ Hunan University of Science and Technology, Hunan Provincial Key Laboratory of High Efficiency \\ and Precision Machining of Difficult to Machine Material, China \\ ${ }^{2}$ Hunan University of Science and Technology, Intelligent Manufacturing Institute, China
}

The capacity to minimize vibrations in grinding by the selection of appropriate process parameters is a significant benefit in the process optimization of cam grinding. This paper presents survey methods to characterize and quantify the vibrations and waviness in a camshaft grinding application. First, a modal analysis was conducted to study the dynamic characteristic of a camshaft grinding machine. Then, developed methods were applied to study the influences of various parameters on vibrations in the high-speed grinding of a camshaft. Furthermore, the influence of each grinding process condition on surface waviness in high-speed camshaft grinding was studied. The results show that the vibrations and the surface waviness change with the increase of grinding depth, and an appropriate grinding wheel speed combined with a workpiece speed has, for most grinding conditions, a reducing effect on vibration magnitudes and waviness. Finally, the specific indications about the optimal grinding process parameters in terms of dynamic characteristics of the grinding machine were given, and the speed ratio=1.2 is a novel choice.

Keywords: vibrations, high-speed grinding, surface waviness, frequency spectrum, camshaft

\section{Highlights}

- An experimental method to analyse the process parameters effects on vibrations in the high-speed grinding of a camshaft is presented.

- The modal analysis enables choosing the favourable frequency range.

- The significant relationships between the features of the process parameters and dynamic characteristic of the camshaft grinder are effectively obtained.

- The optimal grinding process parameters in terms of the dynamic characteristics of the grinding machine are given.

\section{INTRODUCTION}

The camshaft, as a key component in creating a prescribed motion in the contacting element (follower), has been widely used in many industrial fields. Computer numerical control (CNC) camshaft grinders and cubic boron nitride $(\mathrm{CBN})$ wheels have advanced dramatically in recent years and significantly influenced the progress of the high-speed grinding of camshafts [1].

High-speed grinding is often accompanied by complicated vibration behaviours [2]. The cam grinding process is regarded as a typical discontinuous grinding mechanism that includes rapid entries and exits of the grinding wheel into the camshaft accompanied by dynamic grinding depth over the engagement. Vibrations in such conditions are inevitable in the high-speed grinding of a camshaft. Various parameters, including grinding speed, grinding depth, camshaft profile, and machining conditions, play critical roles for the vibrations, while the vibrations in processing acutely affect the wheel life and the ultimate grinding quality. In general, increased vibration magnitude leads to a reduction in grinding wheel life and higher surface waviness.

Two types of vibrations can arise in the high-speed grinding of camshaft: the first type is forced vibrations that originate from the variation in grinding depth and the unbalance of the wheel [3]. These vibrations cause troubles in the grinding processing if their vibration frequency matches one of the natural modes of the machine tool-workpiece system. The second type, known as "chatter", may arise in grinding due to the regenerative and frictional effects of the machine tool-workpiece. An unstable grinding process occurs due to these self-excited vibrations, and the results of grinding wheel wear [4], unacceptable surface finish, and increased noise would arise. In practice, the two types of vibrations above are often present in any grinding operation at the same time even if their impacts on the final result differ.

Much research has been done concerning experimental and analytical grinding vibrations to identify the vibration form during grinding. RoblesOcampo et al. [5] presented a novel nonlinear model for centreless grinding which describes the dynamic behaviour of the process. Zhang et al. [6] proposed 
a non-linear dynamic model to research the dynamic characteristics of the grinding process and the different vibrations resulting in the qualitative behaviour of the grinding machine was demonstrated. Mohammadi and Ahmadi [7] presented an update to the widely used multi-frequency solution of regenerative chatter by modelling the tool dynamics as a linear time-periodic system. In order to investigate the nonlinear, nonautonomous vibration characteristics of a cylindrical traverse grinding process, Jung et al. [8] performed nonlinear analyses applied to a spatially periodic wavy surface. On the basis of mechanical analysis, Zhu et al. [9] researched the chatter stability of grinding thin-walled parts based on the modal experiments of titanium alloy workpiece and grinding head. Denkena et al. [10] presented a system for chatter detection and elimination for external cylindrical grinding machines. Thomazella et al. [11] proposed a new digital processing technique for the monitoring of the chatter phenomenon during the grinding of AISI 1045 steel with various grinding wheels.

It can be seen from the above research that the identification method of vibration form has become essentially mature. However, the vibration behaviour of different processing methods is variational, so the experimental analysis is necessary for exploring the specific form of vibration.

In contrast, the grinding process parameters affect the grinding force and machine dynamic behaviours, and then change the form of vibration and surface waviness. To better establish the relationship between grinding process parameters and stable grinding conditions, the investigations of the grinding vibration mechanism are critical. Cao et al. [12] established a new model for the surface topography of the grinding process to discuss the effects of the wheel vibration amplitude, wheel grit number, as well as process parameters on the surface waviness and roughness. Leonesio et al. [13] presented a novel frequency domain approach for identifying the process parameters, exploiting in-process system response, which measured via impact testing. Liu et al. [14] analysed the process parameters and stability grinding conditions affecting the grinding stability of the bliskblade belt. Rao et al. [15] estimated the influence of various input process parameters on machine tool life by determining the roughness on a machined surface and amplitude of workpiece vibration. Therefore, given that the lessening of vibration is profitable for grinder life and processing precision, it is researching the effects of grinding process parameters and grinding conditions on the dynamic behaviours is necessary.
However, few studies related to the vibrations in high-speed grinding of camshaft have been made. This paper aims to effectively quantify vibration magnitudes and surface waviness, which make it possible to research the effects of the process parameters on the dynamic characteristics in the highspeed grinding of camshaft.

In the following sections, the measurement methods and experimental setup are described. Next, experimental results are presented and discussed. In the final section, conclusions and recommendations are given.

\section{EXPERIMENTAL METHODOLOGY}

The vibration and surface waviness with different grinding speeds and grinding depths have been investigated. The experiments were set to three setups: First, the sampling frequency and analysis spectral line of each test instrument were set, and the interference of the external vibration source to the test signal was observed and eliminated. Second, the vibration acceleration signal of the processing system was collected when the machine was idling with different grinding process parameters, which was compared with the subsequent experimental research. Third, the vibration signal and surface waviness were sampled with different grinding process parameters in the actual machining.

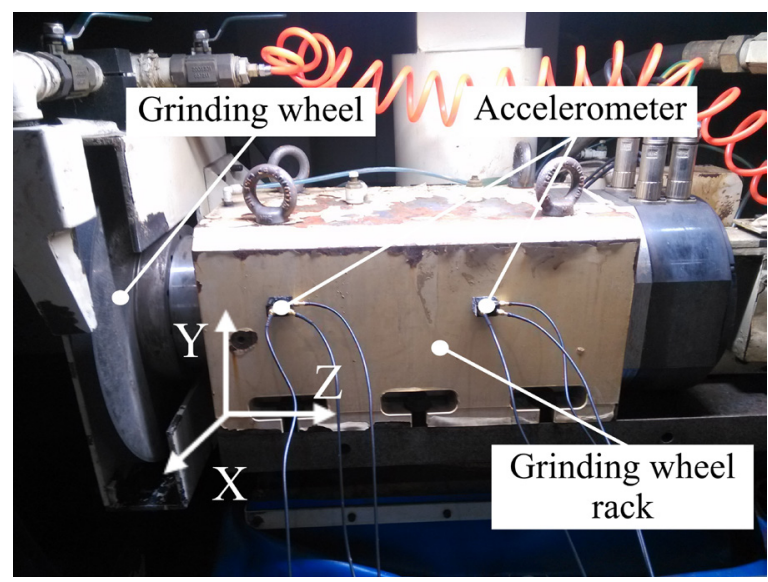

Fig. 1. Accelerometer sensor on the grinding wheel rack

\subsection{Measurement Methods}

The acceleration signal measurements were conducted in a camshaft grinding machine with a three-direction EA-YD-152 piezoelectric acceleration sensor (Econ, China), as shown in Fig. 1. The acceleration sensor 
was glued on the grinding wheel rack. The test platform of vibrations the machine-tool-workpiece system in the high-speed grinding of camshaft is shown in Fig. 2. Acceleration signals in $X, Y$, and $Z$ directions were measured during grinding. The grinding force was measured with a cylindrical grinding dynamometer. The ANVAT Signal Automatic Gathering and Analysis System (Econ, China), and the sample frequency used in the signal collection system was set to $2 \mathrm{kHz}$, which was applied to monitor the vibration of machine tools in the grinding process and gathered data of idling, steadily and occurs chatter in the high-speed grinding process. The surface waviness was detected by MarSurf M300 Surface Roughometer (Mahr, German). The arithmetical mean deviation of the waviness profile was selected as the characteristic parameter of the waviness. The measurement direction of the waviness was parallel to the grinding direction.

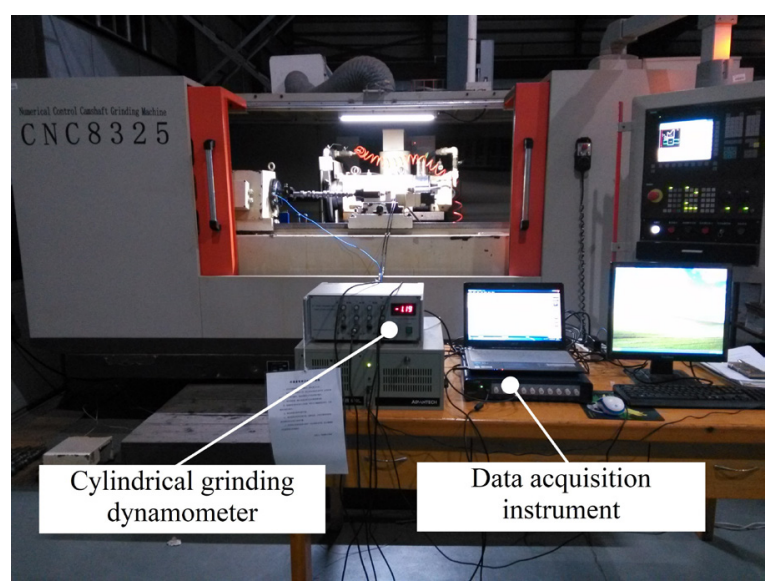

Fig. 2. The test platform of vibrations in high-speed grinding of camshaft

\subsection{Modal Analysis}

Modal analysis of the processing system was accomplished to aid in the in-depth understanding of the dynamic characteristic. The frequency response functions (FRFs) of the processing system were acquired by impact hammer tests. In the tests, modal parameters such as the equivalent mass $(m)$, the stiffness coefficient $(k)$, the structural damping ratio $(\zeta)$, and the natural frequency $\left(w_{n}\right)$ of the processing system were obtained. The acceleration sensor was installed in the feed direction of the grinding machining, and a hammering test was conducted using hammer beats.

The impacting point was located in the grinding wheel rack of the grinding machine while the measuring points were set according to Fig. 1. The three directions were excited, and the corresponding response was measured. From the data shown in Table 1 , it is obvious that the dynamic stiffnesses of the grinding wheel rack in the $X$ direction and $Z$ direction is far less than the dynamic stiffness in the $Y$ direction. The natural modes at $51.8 \mathrm{~Hz}, 77.2 \mathrm{~Hz}, 146.6 \mathrm{~Hz}$, and $176 \mathrm{~Hz}$ are found in the $X$ direction. The mode of the poorest stiffness is the fourth mode in the $X$ direction at $176 \mathrm{~Hz}$, for which the dynamic stiffness is 14100 $\mathrm{N} / \mathrm{m}$.

Table 1. Dynamic stiffness of grinding wheel rack

\begin{tabular}{cccc}
\hline \multirow{2}{*}{ Mode $[\mathrm{Hz}]$} & \multicolumn{3}{c}{ Dynamic stiffness [N/mm] } \\
\cline { 2 - 4 } & $X$ direction & Y direction & Z direction \\
\hline 51.8 & - & 75900 & 15500 \\
\hline 77.2 & 28600 & 34500 & - \\
\hline 105.7 & 18600 & 33400 & 19200 \\
\hline 146.6 & 27100 & 65600 & - \\
\hline 176.0 & 14100 & 61900 & 8471.5 \\
\hline
\end{tabular}

\subsection{Parameters of Experiments}

The experiments were conducted on an ultra-highspeed precision combined grinder (type CNC8325) manufactured by the Hunan Hicam Engineering Technology Research Co. Ltd, China. The grinding wheel is a $70^{\#} \mathrm{CBN}$ grinding wheel with the highest linear speed up to $200 \mathrm{~m} / \mathrm{s}$, and the diamond roller is used for dressing, the dressing parameters are shown in Table 2.

Table 2. Dressing parameter

\begin{tabular}{ccccc}
\hline $\begin{array}{c}\text { Dressing } \\
\text { speed } \\
{[\mathrm{r} / \mathrm{min}]}\end{array}$ & $\begin{array}{c}\text { Grinding } \\
\text { wheel taper } \\
\text { compensation [ }{ }^{\circ} \text { ] }\end{array}$ & $\begin{array}{c}\text { Grinding } \\
\text { wheel } \\
\text { radius [mm] }\end{array}$ & $\begin{array}{c}\text { Value of } \\
\text { dressing } \\
{[\mathrm{mm}]}\end{array}$ & $\begin{array}{c}\text { Idle speed of } \\
\text { grinding wheel } \\
{[\mathrm{mm} / \mathrm{min}]}\end{array}$ \\
\hline 800 & 0 & 200 & 0.003 & 1500 \\
\hline
\end{tabular}

Table 3. Grinding test conditions

\begin{tabular}{lc}
\hline Project & Parameter \\
\hline grinding wheel & $\varphi 400 \times 25 \mathrm{~mm}, \mathrm{CBN}$ \\
\hline camshaft specimen & chilled cast iron \\
\hline grinding-wheel speed, $v_{s}$ & $60 \mathrm{~m} / \mathrm{s}$ to $150 \mathrm{~m} / \mathrm{s}$ \\
\hline workpiece speed, $n_{w}$ & $90 \mathrm{r} / \mathrm{min}$ to $180 \mathrm{r} / \mathrm{min}$ \\
\hline grinding depth, $a_{p}$ & $0.01 \mathrm{~mm}$ to $0.04 \mathrm{~mm}$ \\
\hline
\end{tabular}

A typical cam is used as a sample. The radius of the base circle is $15.5 \mathrm{~mm}$, the workpiece material is chilled cast iron. The grinding conditions used in the experiments are from the production data of the manufacturer, as shown in Table 3, and a series of experiments were conducted with the fractional 
factorial design. The feeding speed of the grinding wheel was set to $4500 \mathrm{~mm} / \mathrm{min}$.

\section{RESULTS AND DISCUSSIONS}

\subsection{Vibration Characteristics of Machine Tools}

The vibration signal was collected in the time domain for all directions. The frequency spectrum analysis method was applied to characterize the acceleration signal in the frequency domain [16]. The frequency spectrum of the vibration signal of idling test and actual process is shown in Fig. 3.

As seen from Fig. 3, A is the maximum vibration amplitude, and $f$ is the frequency when the vibration amplitude is maximum; there are the more intensive low-rising value vibration spectrum peak under the grinding wheel spindle rotation frequency high frequency area. The frequency of vibration amplitude could also increase gradually to more obvious impact on vibration of the processing system with the change of the grinding wheel speed.

The forced vibration is the main vibration source of the processing system, and the vibration force produced by the rotating unbalance of the grinding wheel spindle system is the most important factor that affects vibration of the processing system [17], and which is positively related to grinding velocity. The excitation amplitude is maximum when the grinding velocity $v_{s}=140 \mathrm{~m} / \mathrm{s}$, and the rotation of the grinding wheel spindle system frequency is $112.5 \mathrm{~Hz}$, which is close to the third-order natural frequency of the camshaft high-speed grinding system (105.7 $\mathrm{Hz}$ ); therefore, the main vibration amplitude of the processing system is greater.

Table 4. Comparison of camshaft grinding idling test and actual grinding test $\left(n_{w}=90 \mathrm{r} / \mathrm{min}, a_{p}=0.01 \mathrm{~mm}\right.$ )

\begin{tabular}{ccccc}
\hline \multirow{2}{*}{ Level } & $\begin{array}{c}\text { Grinding } \\
\text { speed }[\mathrm{m} / \mathrm{s}]\end{array}$ & $\begin{array}{c}\text { Frequency } \\
{[\mathrm{Hz}]}\end{array}$ & \multicolumn{2}{c}{ Maximum vibration amplitude [G] } \\
\cline { 4 - 5 } & 60 & 48.34 & Actual process & Idling test \\
\hline 1 & 90 & 77.63 & 1.33 & 1.483 \\
\hline 2 & 120 & 95.21 & 1.512 & 1.79 \\
\hline 3 & 140 & 112.79 & 2.518 & 2.675 \\
\hline 4 & 150 & 120.12 & 1.72 & 2.191 \\
\hline 5 & & & & \\
\hline
\end{tabular}

The comparison of the spectral analysis obtained from the test of idling and actual grinding process is shown in Table 4. Because the effects of grinding damping in the actual grinding [18], the main vibration amplitude of actual process is smaller than the main vibration amplitude of the idling test. However, there
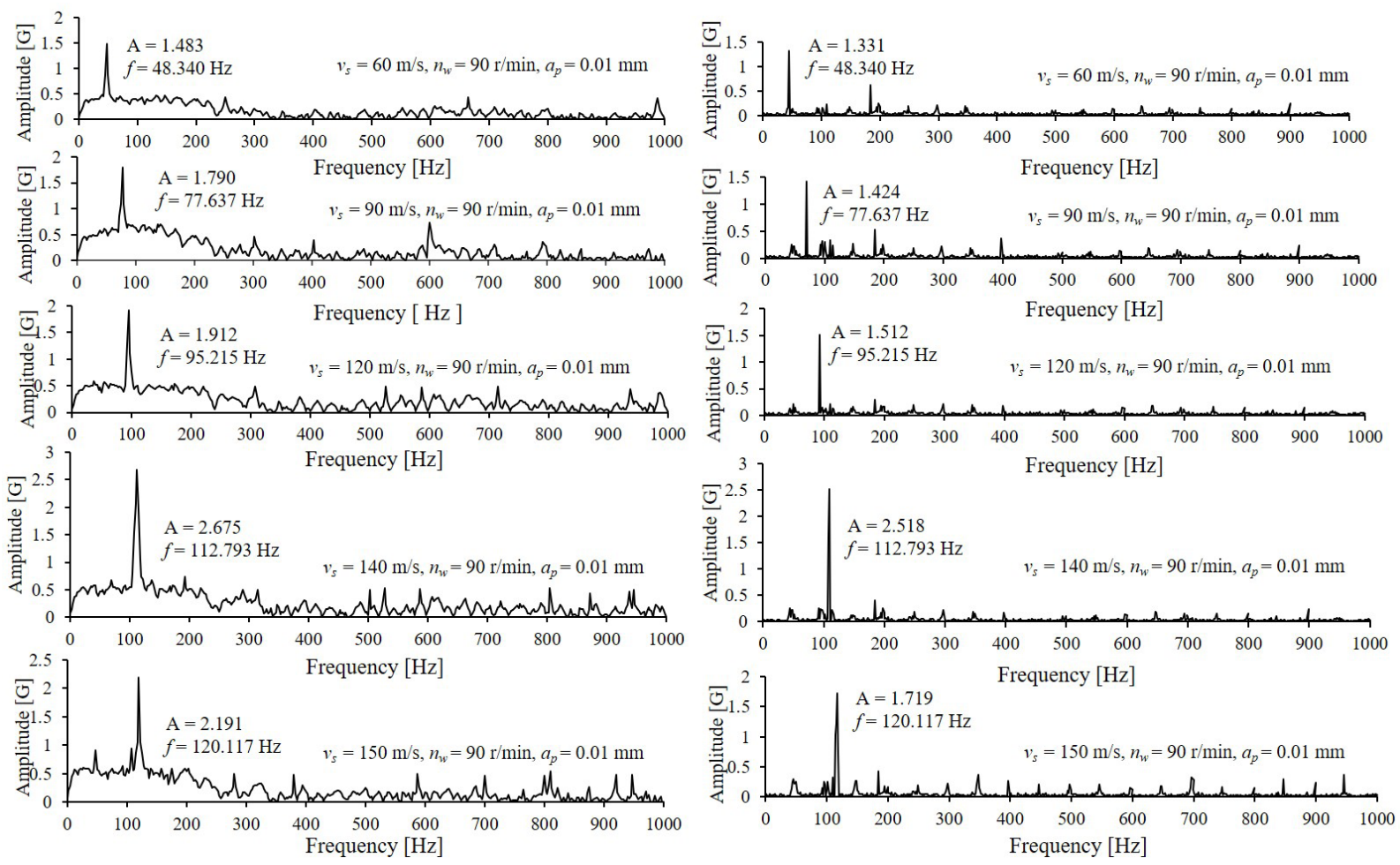

Fig. 3. Frequency spectrum of vibration signal for a) idling test, and b) actual process 
is not much difference between the main vibration frequency in the idling test and actual process, and the value of vibration frequency of both are close to exciting frequency that caused by rotation imbalance of the grinding wheel spindle system.

\subsection{Parameter Effects}

The dynamic characteristic of the processing system changes with the grinding process parameters. The vibration signal of different status of processing system is shown in Fig. 4.

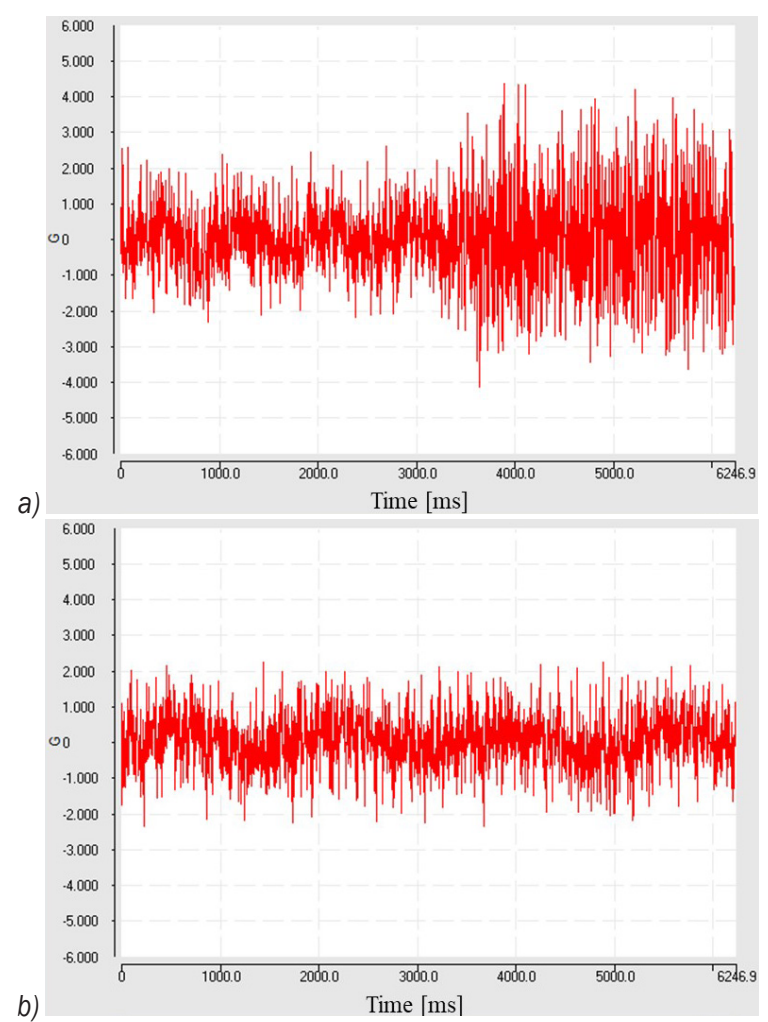

Fig. 4. The different status of processing system: a) unstable, and b) stable

The grinding stability lobes diagram of camshaft was derived, and the grinding process parameters (as shown in Table 5) of vibration testing were marked out with red dots, as shown in Fig. 5.

As shown in Fig. 5, the points of experiments No. 3, 4, 10 ,11, and 12 are above the lobe's envelope of stability in the diagram, which is the instability zone in the grinding process. While the points of experiments No. 1, 5, 6, and 9 are in the inferior of the lobe's envelope that is the stable grinding zone in the grinding process. The points of experiments No. 2, 7, and 8 are located on a critical line of the stability zone and the instability zone in the grinding.
From Fig. 6, it can be seen that forced vibration was dominant in experiments No 1, 2, 5, 6, 7, 8, and 9 . The vibration of the processing system is combined with the forced vibration and self-excited vibration in experiments No. 3, 4, 10,11, and 12, and the influence of self-excited vibration is more significant with the change of the grinding speed and grinding depth. As seen from Table 1, the mode of poorest stiffness is the fourth mode in the $X$ direction at $176 \mathrm{~Hz}$, which the dynamic stiffness is $14100 \mathrm{~N} / \mathrm{m}$, so the chatter is most likely to happen near the fourth mode. According the frequency spectrum analysis, the chatter frequency is $187.5 \mathrm{~Hz}$, which slightly higher than natural frequency of the fourth mode in the $X$ direction, as mentioned in [19].

Table 5. The experimental parameters

\begin{tabular}{ccccc}
\hline \multirow{2}{*}{$\begin{array}{c}\text { Experiment } \\
\text { No. }\end{array}$} & $\begin{array}{c}\text { Grinding } \\
\text { speed [m/s] }\end{array}$ & $\begin{array}{c}\text { Workpiece } \\
\text { speed [r/min] }\end{array}$ & $\begin{array}{c}\text { Grinding } \\
\text { depth [mm] }\end{array}$ & $\begin{array}{c}\text { Feeding } \\
\text { speed } \\
{[\mathrm{mm} / \mathrm{min}]}\end{array}$ \\
\hline 1 & 60 & 90 & 0.01 & 4500 \\
\hline 2 & 60 & 90 & 0.02 & 4500 \\
\hline 3 & 60 & 90 & 0.03 & 4500 \\
\hline 4 & 60 & 90 & 0.04 & 4500 \\
\hline 5 & 120 & 90 & 0.01 & 4500 \\
\hline 6 & 120 & 90 & 0.02 & 4500 \\
\hline 7 & 120 & 90 & 0.03 & 4500 \\
\hline 8 & 120 & 90 & 0.04 & 4500 \\
\hline 9 & 140 & 90 & 0.01 & 4500 \\
\hline 10 & 140 & 90 & 0.02 & 4500 \\
\hline 11 & 140 & 90 & 0.03 & 4500 \\
\hline 12 & 140 & 90 & 0.04 & 4500 \\
\hline
\end{tabular}

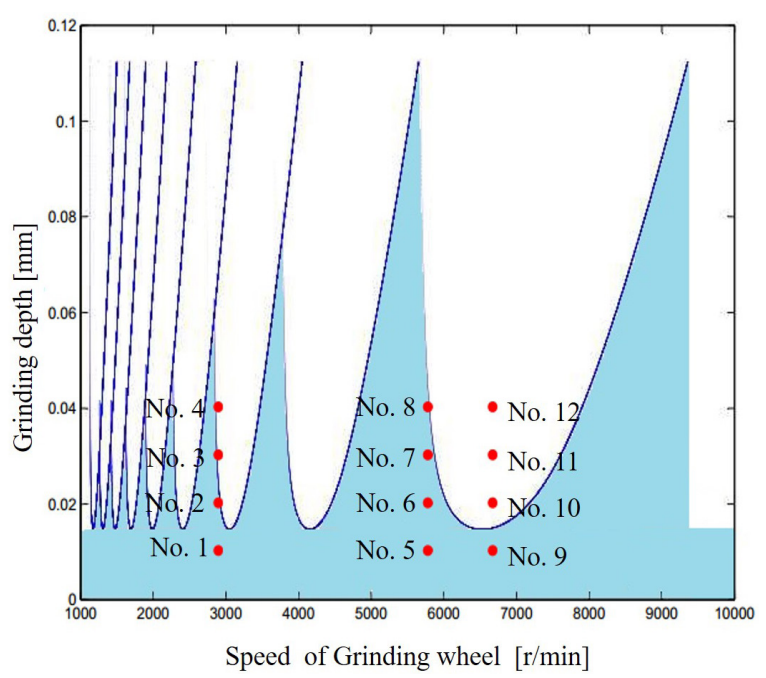

Fig. 5. Grinding stability lobes diagram

The acquired results indicate a clear difference in vibrational characteristic rest with the grinding 

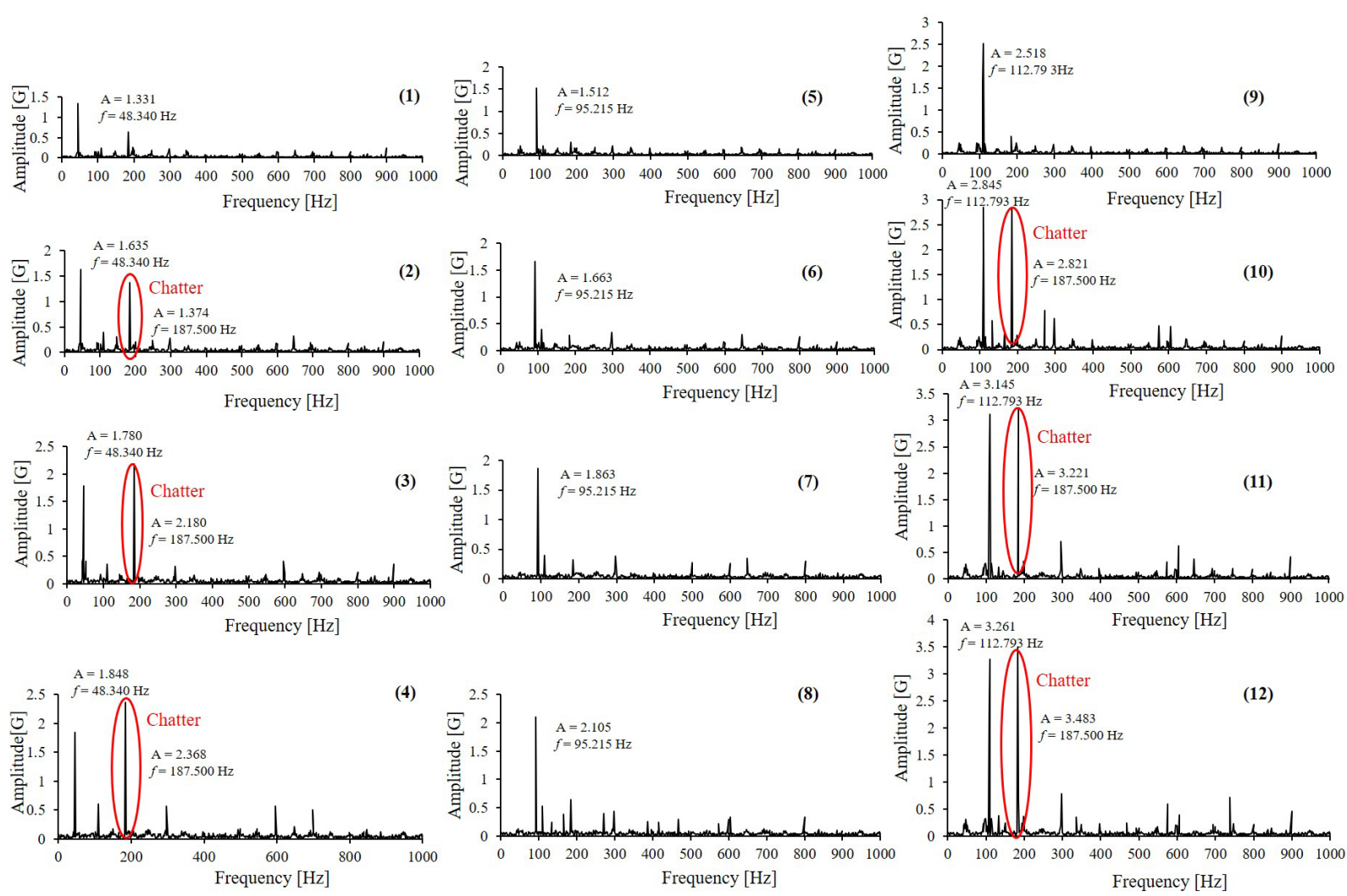

Fig. 6. Vibration signal spectrum of camshaft grinding

process parameters. Although vibration is inevitable during machining, machining process parameters could be reasonably selected to reduce self-excited vibration and resonance in the high-speed grinding process of camshaft.

\subsection{Surface Waviness}

The vibrations of the grinding wheel system are the main reason for surface waviness in grinding. The variation of the grinding process parameters leads to the change of system grinding force, geometric interference, dynamic stiffness, etc., and then affects the surface waviness of the workpiece. To study the influence of each grinding process conditions on surface waviness in high-speed camshaft grinding, in this paper, a Motif algorithm was used to evaluate the surface topography after obtaining the original contour information of surface topography, and the separation calculation of surface waviness of the workpiece was completed.

The average depth of corrugation on the curve was as the evaluation index of the surface waviness $(W)$ of high-speed grinding of camshaft, and its numerical calculation is shown in Eq. (1):

$$
W=\frac{1}{2 n} \sum_{j=1}^{2 n} W_{j},
$$

where $W_{j}$ is corrugation value of point $j, j=1,2, \ldots, 2 n$. The maximum value of waviness is usually above the grain direction of grinding. Therefore, the surface topography of the camshaft after high-speed grinding was measured along the grain direction, and its original contour curve was obtained, as shown in Fig. 7.

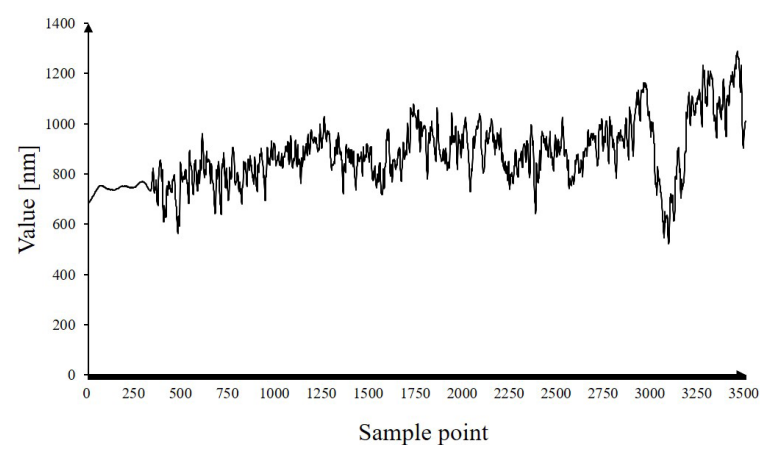

Fig. 7. The original contour curves

Fig. 8 shows that the camshaft surface roughness quality obtained by grinding with the grinding 
process parameters in this test meets the processing requirements and the surface waviness values of experiments No. 3, 4, 10, 11, and 12 are much higher than that of experiments No. 1, 5, 6, and 9, while the waviness values of experiments No. 2, 7, and 8 are in the middle range. According to vibration spectrum analysis in the process of grinding system and stability lobes diagram analysis, the tests of experiments No. 1, 5,6 , and 9 are in the stable zone of grinding, and the self-excited vibration does not occur, so the quality of grinding surface is good. and values of the surface waviness are less than 0.5 microns.

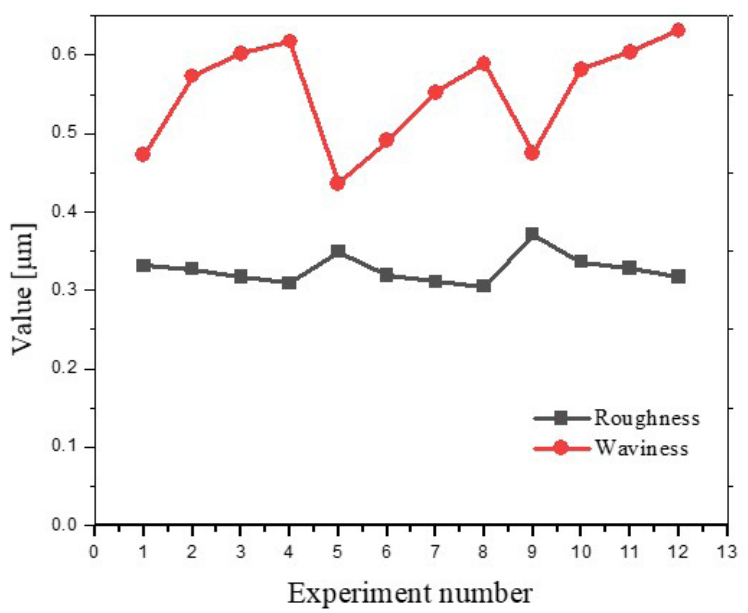

Fig. 8. Test results of roughness and waviness

To further analyse the influence of different grinding process parameters (grinding speed, workpiece speed, and grinding depth) on surface waviness, orthogonal tests with three factors and four levels were carried out on the representative process parameters in the stability lobe diagram. The degree of influence of the three factors were investigated with range analysis and variance analysis.

The comparative analysis of the mean value $\left(\alpha_{i}\right.$, $\beta_{i}, \gamma_{i}, \delta_{i}$ ) in Table 6 indicated that the range of the influence of the grinding parameters to the surface waviness is grinding depth, grinding velocity, and workpiece speed, where $\alpha_{i}, \beta_{i}, \gamma_{i}, \delta_{i}$ represents the average value of the surface waviness corresponding to Level 1, 2, 3, and 4 of column $i$ in the orthogonal table and $R_{i}$ is the range of the surface waviness . The value of $F$ (ratio of the variance of the sample mean and the error variance, which represent the significance level) and value of significance level in Table 7 shows the same conclusion as in Table 6.

Surface waviness is a positively correlated relationship with grinding depth, and the influence mechanism of the grinding velocity and workpiece speed on surface waviness is more complicated [20]; there is obvious interaction between the grinding velocity and workpiece rotational speed.

Table 6. Result of test and range analysis

\begin{tabular}{|c|c|c|c|c|}
\hline Project & $\begin{array}{c}\text { Grinding } \\
\text { speed }[\mathrm{m} / \mathrm{s}]\end{array}$ & $\begin{array}{c}\text { Workpiece } \\
\text { speed } \\
\text { [r/min] }\end{array}$ & $\begin{array}{c}\text { Grinding } \\
\text { depth [mm] }\end{array}$ & $\begin{array}{c}\text { Waviness } \\
{[\mu \mathrm{m}]}\end{array}$ \\
\hline 1 & 90 & 90 & 0.01 & 0.445 \\
\hline 2 & 90 & 120 & 0.02 & 0.494 \\
\hline 3 & 90 & 150 & 0.03 & 0.558 \\
\hline 4 & 90 & 180 & 0.04 & 0.649 \\
\hline 5 & 120 & 90 & 0.02 & 0.491 \\
\hline 6 & 120 & 120 & 0.01 & 0.429 \\
\hline 7 & 120 & 150 & 0.04 & 0.597 \\
\hline 8 & 120 & 180 & 0.03 & 0.567 \\
\hline 9 & 140 & 90 & 0.03 & 0.604 \\
\hline 10 & 140 & 120 & 0.04 & 0.625 \\
\hline 11 & 140 & 150 & 0.01 & 0.460 \\
\hline 12 & 140 & 180 & 0.02 & 0.578 \\
\hline 13 & 150 & 90 & 0.04 & 0.619 \\
\hline 14 & 150 & 120 & 0.03 & 0.595 \\
\hline 15 & 150 & 150 & 0.02 & 0.488 \\
\hline 16 & 150 & 180 & 0.01 & 0.437 \\
\hline$\alpha_{i}$ & 0.5365 & 0.5397 & 0.4428 & \\
\hline$\beta_{i}$ & 0.5210 & 0.5357 & 0.5228 & \\
\hline$\gamma_{i}$ & 0.5667 & 0.5257 & 0.5810 & \\
\hline$\delta_{i}$ & 0.5347 & 0.5577 & 0.6225 & \\
\hline$R_{i}$ & 0.0458 & 0.032 & 0.1798 & \\
\hline
\end{tabular}

Table 7. Test variance analysis

\begin{tabular}{lccccc}
\hline Factor & $\begin{array}{c}\text { Sum of } \\
\text { squares }\end{array}$ & DOF & $\begin{array}{c}\text { Mean } \\
\text { square }\end{array}$ & F & Sig. \\
\hline Grinding speed & 0.0044645 & 3 & 0.0014882 & 3.67 & 0.082 \\
\hline Grinding depth & 0.0747485 & 3 & 0.0249162 & 61.47 & 0.000 \\
\hline Workpiece speed & 0.0024320 & 3 & 0.0007147 & 1.76 & 0.254 \\
\hline
\end{tabular}

Via matching process parameters with machine dynamics, more stable machining results can be obtained [21] and [22]. Fig. 9 shows the change of surface waviness in the grinding process with different linear speeds $\left(v_{s}=90 \mathrm{~m} / \mathrm{s}, v_{s}=120 \mathrm{~m} / \mathrm{s}, v_{s}\right.$ $=140 \mathrm{~m} / \mathrm{s}$, and $\left.v_{s}=150 \mathrm{~m} / \mathrm{s}\right)$ and the grinding depth remains unchanged, $a_{p}=0.01 \mathrm{~mm}$. The speed ratio is the ratio of grinding speed to workpiece speed, which is dimensionless.

It is seen from Fig. 9, with the increased speed ratio, the surface waviness value decreases firstly and then increases; it reaches the optimal value when the speed ratio is 1.2. It is thought that when the workpiece speed continues to increase, the grinding wheel acceleration and jerk become greater because the complexity of non-circular profile shapes, the 
overcut or undercut may be happened in the tangential point tracing grinding process. In particular, the linear speed of grinding wheel is above $140 \mathrm{~m} / \mathrm{s}$, this phenomenon is more obvious, and the vibration of the processing system intensifies, which leads to higher waviness on the surface of camshaft machining.

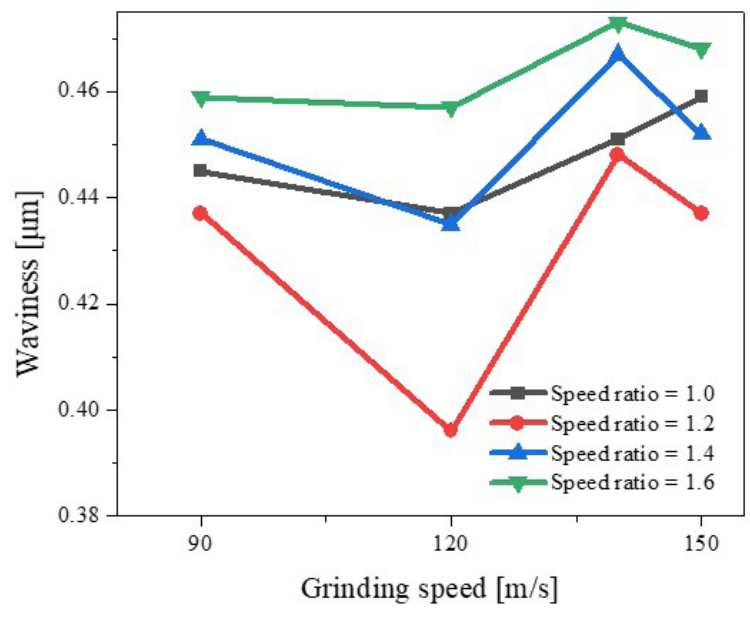

Fig. 9. Results under different speed ratio

At the same grinding speed ratio, with the grinding speed in a certain range $(90 \mathrm{~m} / \mathrm{s}$ to $120 \mathrm{~m} / \mathrm{s})$ increasing, normal grinding force is reduced and the grinding processing system is in a stable condition, so the surface waviness become lower. With speed of grinding wheel at $130 \mathrm{~m} / \mathrm{s}$ to $140 \mathrm{~m} / \mathrm{s}$, although the normal grinding force has diminished constantly, but the frequency of grinding wheel spindle system is close to the natural frequency, so vibration amplitude of grinding process system increases, and the surface waviness value becomes larger. As the grinding speed increases to $150 \mathrm{~m} / \mathrm{s}$, the surface waviness is lower due to the grinding wheel frequency being away from the natural frequency of the processing system.

The above investigations have significance for the optimization of processing parameters based on efficient and stable targets. In the actual grinding processing of the camshaft, the following process condition optimization strategies can be adopted to control the waviness:

- In the high-speed camshaft grinding, the grinding speed is recommended to be selected within the range near $120 \mathrm{~m} / \mathrm{s}$ and as far as possible to avoid natural frequency of the processing system.

- The rotation speed of the workpiece should be selected appropriately, appropriate grinding wheel speed combined with a relatively workpiece speed has a reducing effect on vibration magnitudes and waviness for the most of grinding conditions, and the speed ratio 1.2 is a novel choice.

\section{CONCLUSIONS}

An experimental method to analyse the process parameters effects on vibrations in high-speed grinding of camshaft is presented. The modal analysis enables choosing the favourable frequency range. The significant relationships between the features of the process parameters and the dynamic characteristic of the camshaft grinder are effectively obtained, i.e. the influence of the different grinding speeds and grinding depths on vibration magnitudes and surface waviness. The obtained results strongly demonstrate that the presented methods can be available in evaluation of grinding process parameters in order to lessen vibrations in camshaft grinding. The quantization of vibration magnitudes and surface waviness for the different process parameters used in the tests identify the best selection for specific grinding parameters. It also demonstrates that the grinding speed $v_{s}=120$ $\mathrm{m} / \mathrm{s}$ gives lowest vibrations in the experiments and higher vibrations with the increasing of grinding depth. It is confirmed by the survey of the frequency domain in which it was shown that a lower dynamic stiffness can, under some conditions, exhibit an unstable appearance which causes increased vibration magnitudes. The most significant factor of grinding surface waviness is the grinding depth. The result of speed ratio grinding test is a vital guideline for the design of process schemes. Additional research is needed to determine whether the different profiles of camshaft have a significant effect on vibration amplitudes. Further investigations are necessary to clarify the impact of grinding wheel wear in relation to vibrations and surface waviness.

\section{ACKNOWLEDGEMENTS}

This research was financially supported by the project of Hunan Provincial Innovation Foundation for Postgraduate (Grant No. CX20190792), the Natural Science Foundation of Hunan province (Grant No. 2017JJ4007) and the National Science and Technology Major Project (Grant No. 2018ZX04035002-005).

\section{REFERENCES}

[1] Tang, H., Deng, Z.H., Guo, Y.S., Qian, J., Reynaerts, D. (2014). Research on constant grinding depth model for cam grinding. The International Journal of Advanced Manufacturing 
Technology, vol. 74, no. 1-4, p. 351-359, D0l:10.1007/s00170014-5993-2.

[2] Wegener, K., Bleicher, F., Krajnik, P., Hoffmeister, H.W., Brecher, C. (2017). Recent developments in grinding machines. CIRP Annals, vol. 66, no. 2, p. 779-802, DOl:10.1016/j.cirp.2017.05.006.

[3] Zhang, S., Yu, J., To, S., Xiong, Z. (2018). A theoretical and experimental study of spindle imbalance induced forced vibration and its effect on surface generation in diamond turning. International Journal of Machine Tools and Manufacture, vol. 133, p. 61-71, D0l:10.1016/j. ijmachtools.2018.06.002.

[4] Aleksandrova, I.S. (2019). Multi-objective optimization of the dressing parameters in fine cylindrical grinding. Strojniški vestnik - Journal of Mechanical Engineering, vol. 65, no. 2, p. 87-102, D0I:10.5545/sv-jme.2018.5677.

[5] Robles-Ocampo, J.B., Jauregui-Correa, J.C., Krajnik, P., SevillaCamacho, P.Y., Herrera-Ruiz, G. (2012). Nonlinear model for the instability detection in centerless grinding process. Strojniški vestnik - Journal of Mechanical Engineering, vol. 58, no. 12, p. 693-700, D0l:10.5545/sv-jme.2012.649.

[6] Zhang, N., Kirpitchenko, I., Liu, D.K. (2005). Dynamic model of the grinding process. Journal of Sound and Vibration, vol. 280, no. 1-2, p. 425-432, D0l:10.1016/j.jsv.2003.12.006.

[7] Mohammadi, Y., Ahmadi, K. (2019). Frequency domain analysis of regenerative chatter in machine tools with linear time periodic dynamics. Mechanical Systems and Signal Processing, vol. 120, p. 378-391, D0l:10.1016/j. ymssp.2018.10.029.

[8] Jung, J., Kim, P., Kim, H., Seok, J. (2015). Dynamic modeling and simulation of a nonlinear, non-autonomous grinding system considering spatially periodic waviness on workpiece surface. Simulation Modelling Practice and Theory, vol. 57, p. 88-99, D0I:10.1016/j.simpat.2015.06.005.

[9] Zhu, L., Yang, Z., Li, Z. (2019). Investigation of mechanics and machinability of titanium alloy thin-walled parts by CBN grinding head. The International Journal of Advanced Manufacturing Technology, vol. 100, no. 9-12, p. 2537-2555, DOl:10.1007/s00170-018-2795-y.

[10] Denkena, B., Ortmaier, T., Bergmann, B., Schreiber, P., Ahrens, M., Damm, J. (2019). Suitability of integrated sensors for the determination of chatter characteristics in a cylindrical grinding machine. The International Journal of Advanced Manufacturing Technology, vol. 102, no. 5-8, p. 2339-2344, DOI:10.1007/s00170-019-03323-y.

[11] Thomazella, R., Lopes, W.N., Aguiar, P.R., Alexandre, F.A., Fiocchi, A.A., Bianchi, E.C. (2019). Digital signal processing for self-vibration monitoring in grinding: A new approach based on the time-frequency analysis of vibration signals. Measurement, vol. 145, p. 71-83, D0l:10.1016/J.measurement.2019.05.079.

[12] Cao, Y., Guan, J., Li, B., Chen, X., Yang, J., Gan, C. (2013). Modeling and simulation of grinding surface topography considering wheel vibration. The International Journal of Advanced Manufacturing Technology, vol. 66, no. 5-8, p. 937945, D0I:10.1007/s00170-012-4378-7.

[13] Leonesio, M., Parenti, P., Bianchi, G. (2017). Frequency domain identification of grinding stiffness and damping. Mechanical Systems and Signal Processing, vol. 93, p. 545558, DOI:10.1016/j.ymssp.2017.02.028.

[14] Liu, Y., Li, Q., Xiao, G., Huang, Y. (2019). Study of the vibration mechanism and process optimization for abrasive belt grinding for a blisk-blade. IEEE Access, vol. 7, p. 2482924842, DOI:10.1109/ACCESS.2019.2899495.

[15] Rao, K.V., Murthy, B.S.N., Mohan Rao, N. (2015). Experimental study on surface roughness and vibration of workpiece in boring of AISI 1040 steels. Proceedings of the Institution of Mechanical Engineers, Part B: Journal of Engineering Manufacture, vol. 229, no. 5, 703-712, DOI:10.1177/0954405414531247.

[16] Thaler, T., Potočnik, P., Kopač, J., Govekar, E. (2014). Experimental chatter characterization in metal band sawing. Strojniški vestnik - Journal of Mechanical Engineering, vol. 60, no. 4, p. 265-273, D0l:10.5545/sv-jme.2013.1515.

[17] Badger, J., Murphy, S., O'Donnell, G. (2011). The effect of wheel eccentricity and run-out on grinding forces, waviness, wheel wear and chatter. International Journal of Machine Tools and Manufacture, vol. 51, no. 10-11, p. 766-774, D0l:10.1016/j.ijmachtools.2011.06.006.

[18] Muhammad, B.B., Wan, M., Feng, J., Zhang, W.H. (2017). Dynamic damping of machining vibration: a review. The International Journal of Advanced Manufacturing Technology, vol. 89, no. 9-12, p. 2935-2952, D0l:10.1007/s00170-0169862-z.

[19] Shrivastava, Y., Singh, B. (2019). A comparative study of EMD and EEMD approaches for identifying chatter frequency in CNC turning. European Journal of Mechanics-A/Solids, vol. 73, 381-393, D0l:10.1016/j.euromechsol.2018.10.004.

[20] Parenti, P., Leonesio, M., Cassinari, A., Bianchi, G., Monno, M. (2015). A model-based approach for online estimation of surface waviness in roll grinding. The International Journal of Advanced Manufacturing Technology, vol. 79, no. 5-8, p. 1195-1208, Dol:10.1007/s00170-015-6864-1.

[21] Chen, Y., Chen, X., Xu, X., Yu, G. (2018). Effect of energy consumption in the contact zone on machining condition optimization in precision surface grinding. Strojniški vestnik Journal of Mechanical Engineering, vol. 64, no. 4, p. 233-244, DOI:10.5545/sv-jme.2017.4995.

[22] Wang, C., Zhang, X., Yan, R., Chen, X., Cao, H. (2019). Multi harmonic spindle speed variation for milling chatter suppression and parameters optimization. Precision Engineering, vol. 55, p. 268-274, D0l:10.1016/j. precisioneng.2018.09.017. 